\title{
LA RELACIÓN DE CAUSALIDAD: ¿QUAESTIO FACTI O QUAESTIO IURIS?
}

\section{Comentario a sentencia de Corte Suprema, 26 de enero de $2004^{*}$}

\author{
Hugo A. Cárdenas ${ }^{* *}$
}

\section{INTRODUCCIÓN}

La relación de causalidad ha sido tradicionalmente referida y entendida como uno de los elementos o partes esenciales de la responsabilidad civil. En línea de principio, esta afirmación resulta del todo correcta, ya que carecería de sentido imputar una sanción jurídica a un sujeto que actuó, sin que entre su acción y el resultado dañoso medie un nexo causal. Contrasta con la anterior afirmación el hecho de que la mentada relación de causalidad no haya sido estudiada por la doctrina, salvando honrosas excepciones, con el correlativo entusiasmo ${ }^{1}$. Pero es que la relación de causalidad reviste la particularidad de pasar completamente inadvertida en determinadas ocasiones, mientras que en otras, reviste una importancia fundamental ${ }^{2}$.

Por su parte, tampoco la jurisprudencia nacional ha explotado significativamente el tema del nexo causal, siendo su análisis en la mayoría de los casos vacilante y de poca profundidad. De cualquier manera, a efectos de fijar un punto de partida para nuestro comentario, la postura de las Cortes chilenas se puede sintetizar de la siguiente manera: en primer lugar, exige como requisito para atribuir la responsabilidad civil la existencia de un nexo causal ${ }^{3}$; en segundo, en la mayoría de los casos adscribe y aplica la clásica teoría de la

\footnotetext{
*Jurisprudencia comentada: "Ariztía Comercial Ltda. con Banco Sudamericano". Recurso de casación. Materia: Sobre el control de la relación de causalidad mediante el recurso de casación. Disposiciones aplicables: Artículos 1439, 2314, 2330 y 2399 del Código Civil, y 772, 765, 767, y 805 del Código de Procedimiento Civil.

Doctrina: La relación de causalidad está compuesta por dos elementos: uno naturalístico, y otro normativo. El elemento normativo encierra elementos y aspectos de derecho y, como tal, es susceptible de ser revisado por la Corte Suprema mediante el recurso de casación en el fondo.

(La sentencia a propósito de la cual hice el comentario que aparece a continuación fue publicada en la Gaceta Jurídica, No 283, correspondiente al mes de enero del año 2004, pp. 121-137).

** Abogado. Universidad Complutense de Madrid. Doctorando. Pontificia Universidad Católica de Chile

${ }^{1}$ En la doctrina chilena no pueden pasarse por alto los estudios sobre causalidad de CORRAL TALCIANI, Hernán (2004). Del mismo autor (2003). BARAOnA, Jorge (2003) pp. 345 a 379. ARAYA JaSMA, Fernando (2003). DOMínguez (2000) pp. 115-127.

${ }^{2}$ Cfr. Geri (1967). A pesar de la complejidad del problema, son varios e importantes los autores que han señalado la importancia de una correcta conceptualización del problema causal, llegando algunos a convertirlo en la clave del problema de la teoría de la responsabilidad civil. Sobre los distintos problemas causales puede verse, DE CUEVILLAS (2000) pp. 44 y 45.

${ }^{3}$ Los sentenciadores chilenos han entendido que el legislador al prescribir: quien "ha inferido daño a otro" -art. 2314 del Código Civil-, o "el que hizo el daño está obligado a la indemnización" -art. 2316-, o "el ebrio es responsable por el daño que cause” -art. 2318-, lo que está haciendo es determinar implícitamen-
} 
equivalencia de condiciones ${ }^{4}$; y en tercero, considera la relación causal una simple cuestión de hecho, que por la misma razón, no es susceptible de ser revisada en casación ${ }^{5}$.

Nuestro comentario viene a propósito de una sentencia de la Corte Suprema de Justicia, a la que no le cabe otro calificativo que el de revolucionaria. En efecto, la sentencia que emitió la más alta magistratura chilena el 26 de enero de 2004 (causa no 2.947-02), se aparta claramente de la teoría de la equivalencia de condiciones al analizar la relación de causalidad, entendiendo que la misma se desdobla en dos aspectos: uno naturalístico, respecto del cual la causalidad es una cuestión estrictamente de hecho, y otro normativo, que encierra aspectos y elementos de derecho. Por último, y contraviniendo lo que había sido un lugar común en la judicatura chilena, la Corte entiende que en cuanto a los elementos de derecho que encierra la causalidad, la misma es susceptible de ser revisada en casación, cosa que efectivamente hizo en este fallo que además es, a nuestro parecer, el primero de este tipo en la jurisprudencia chilena.

No creemos necesario insistir en la importancia y trascendencia del fallo objeto de nuestro estudio por lo que, sin más, debemos pasar ahora a desarrollar nuestro comentario. El mismo se llevará a cabo en dos partes principales que se identifican respectivamente con los antecedentes (I) teóricos (A) y prácticos (B) de la sentencia en comento; y con la decisión (II) en sí misma considerada (A), como en sus posibles proyecciones (B).

El plan recién trazado solo se verá alterado al inicio, pues para una mejor comprensión de lo que diremos a continuación, resulta conveniente hacer una breve reseña de los hechos en que se fundaron las pretensiones de las partes litigantes. Veámoslo.

\section{HECHOS RELEVANTES}

Los hechos que originaron el conflicto que nuestra sentencia viene a resolver, tuvieron lugar en la ciudad de Talca y sintéticamente se pueden resumir de la siguiente manera:

te la exigencia del requisito de la causalidad. Más explícitamente se pronuncia el legislador cuando ha tenido la oportunidad de regular los sistemas sectoriales de responsabilidad, v. gr., en el art. 171 de la Ley de Tránsito No 18.290, dice: "El mero hecho de la infracción no determina necesariamente la responsabilidad del infractor si no existe relación de causa a efecto entre la infracción y el daño producido por el accidente". Un tanto de lo mismo sucede en la Ley sobre Bases Generales del Medio Ambiente No 19.300, y en la Ley de Bases Generales de la Administración del Estado n ${ }^{\circ}$ 18.175.

${ }^{4}$ Cfr. C. Sup. 16 de octubre de 1954 , RDJ, t. LI, sec. $1^{\text {a }}$, p. 488. En esta sentencia la Corte afirma que la relación de causalidad "debe entenderse en su sentido natural y obvio... Entre un acto ilícito y un determinado daño si el primero engendra al segundo y este no puede darse sin aquel”. Nótese que es la misma concepción que se maneja en la obra de uno de los clásicos del derecho chileno, así cfr. ALESSANDRI RODRÍGUEZ (1943) no 151.

${ }^{5}$ Prueba de ello es la Sentencia que emitió la Corte Suprema el 4 de enero de 1996, y que en lo medular dice que "determinar la relación de causalidad es una cuestión de hecho que los jueces del fondo establecen privativamente y que escapa a la potestad del tribunal de casación en el fondo, por cuanto el recurso de casación, por su propia naturaleza, no tiene otra finalidad que la de examinar errores de derecho contenidos en la sentencia sobre la base de los hechos establecidos y considerados en el ámbito exclusivo de sus atribuciones." La misma argumentación fue mantenida sistemáticamente en Corte Suprema, 7 de mayo de 1992 , en $R D J$, t. 89, sec. $1^{\text {a }}$, pp. 41 y ss; Corte Suprema, 16 de octubre de 1954 , en $R D J$, t. 51, sec. $1^{\text {a }}$, pp. 488 y ss; Corte Suprema, 14 de abril de 1953, en RDJ, t. 50, sec 4a , pp. 40 y ss. 
Con ocasión del protesto de algunos cheques, la Sociedad ACL dio inicio a los trámites que preparan la vía ejecutiva, procediendo a efectuar la notificación que la ley prescribe en la dirección del girador del cheque que tenía registrado el banco emisor de los cheques. Mas, la mentada notificación no fue realizada en el domicilio que correspondía al girador del cheque, puesto que el Banco Sudamericano, a la sazón, la institución financiera emisora de los cheques, e incumpliendo la normativa respectiva, no comprobó correctamente el domicilio del cuentacorrentista.

A consecuencia del error en la notificación, prosperó un recurso de nulidad contra el protesto, resultando a fin de cuentas anulado el procedimiento; y frustrándose finalmente el cobro de los cheques protestados (se frustró la acción penal que otorga el delito de giro doloso de cheques, y la acción ejecutiva).

Deducida la demanda de indemnización de perjuicios en contra de la entidad bancaria, la Juez titular de Talca acoge la demanda, y condena al demandado a pagar la suma de 31.124.499 pesos. Dicha sentencia es revocada por la corte de apelaciones, la que básicamente entendió que se había roto el nexo causal entre la actuación negligente del banco y la frustración de las acciones de cobro, pues ese hecho no puede "imputarse únicamente al error del Banco Sudamericano demandado en autos", ya que a juicio del tribunal de apelaciones, el demandante tuvo múltiples oportunidades de realizar válidamente y no constando entre los antecedentes el haberlo intentado.

Llevada a casación la sentencia pronunciada por la Corte de apelaciones, se presenta el interesante problema al que ya nos referimos más arriba y sobre el que reincidiremos más abajo, de si la causalidad ha de ser entendida como una cuestión de hecho, o si por el contrario, debe ser tenida como una cuestión de derecho y por tanto apta para ser conocido por el tribunal de casación. Como también ya habíamos adelantado, en un fallo sin precedentes en la historia de la jurisprudencia nacional, la Corte Suprema entiende que la cuestión causal importa, cuando menos un componente normativo, y como tal susceptible de ser revisado en casación, lo que hace casando la sentencia recurrida y confirmando la sentencia apelada (primera instancia).

\section{LOS ANTECEDENTES DEL FALLO}

Como indicamos al introducir este comentario, dedicaremos esta primera parte a repasar los antecedentes que dieron lugar al fallo. Ello se llevará a cabo en dos partes, que respectivamente tratarán de la cuestión desde un punto de vista puramente teórico (A); y desde el punto de vista, mucho más práctico, desde donde la jurisprudencia suele tratar los problemas jurídicos (B).

\section{A. El MARCO TEÓRICO}

En términos simples, el nexo o relación de causalidad que se exige como elemento esencial para que se pueda afirmar la responsabilidad civil, se refiere a que el hecho dañino, es decir, que la conducta a la cual en principio dirigimos nuestro reproche debe 
ser la generadora y, por tanto, causa del daño, al que también en principio, consideramos injusto.

Pero esta relación o nexo causal que recién describimos en términos relativamente sencillos, oculta grandes complejidades, siendo una de las más relevantes, el problema procesal de determinar si dicha relación de causalidad hace referencia a una "cuestión de hecho" o una "cuestión de Derecho". Tal distinción, mantenida con firmeza por la dogmática jurídica ${ }^{6}$ sobre todo desde el movimiento codificador y, casi con exclusividad a propósito del recurso de casación; dice relación con lo que ha sucedido o acontecido en el mundo real (cuestión de hecho), y con la manera en que ha de clasificarse y determinarse lo sucedido, atendiendo a los distintos criterios contenidos en el ordenamiento jurídico (cuestión de derecho) ${ }^{7}$.

Empero, y a pesar de que la distinción ha sido mantenida como una categoría lógica y consustancial a la ciencia jurídica, las nuevas metodologías de estudio del Derecho -en especial las teorías de la argumentación y de la filosofía jurídica en general-, empiezan a cuestionar la distinción, así como a remover la gran capa de sedimento jurídico que, pausadamente se ha ido asentado sobre la misma. En esa línea de pensamiento se instala la idea de Perelman, de que en la ciencia del derecho no se puede separar netamente valoración y conocimiento, y que tampoco se pueden separar los juicios de valor de los juicios de hecho en la aplicación del derecho ${ }^{8}$. En Argentina, Morello, refiriéndose al recurso de casación -pero a nuestro juicio, dando señales de lo artificioso de la distinción-, entiende que el recurso, tal y como se vive en la práctica cotidiana (en el derecho vivo), no puede dejar de controlar por igual al juicio de derecho como al juicio de hecho, pues, corresponde inexcusablemente a la Corte, en supuestos debidamente acreditados, "expurgar y rectificar los juicios de hecho" 9 .

Sea como sea, y nos detendremos aquí, pues nuestra intención en este subapartado corresponde únicamente mostrar el trasfondo teórico del problema, en la actualidad el distingo entre cuestiones de hecho y cuestiones de derecho, tiene importantes consecuencias prácticas. $\mathrm{Y}$ es precisamente ello lo que ha venido sucediendo en Chile con la relación de causalidad, relación que al haber sido históricamente considerada

\footnotetext{
${ }^{6}$ Algunos autores han señalado la codificación decimonónica como el momento en que se acentúa deliberadamente la distinción entre las cuestiones de hecho y las cuestiones de derecho. Al respecto, señala GROSSI (2003) pp. 81 y ss., que en el proyecto jurídico burgués, "compacta e impenetrable es la muralla china que separa el mundo del derecho (y de la relevancia jurídica) del mundo de los hechos (y de la irrelevancia jurídica), tan compacta e impenetrable como quizá nunca se había logrado en los largos tiempos de la historia jurídica occidental".

7 LARENZ (2001) p. 303. En el texto citado, el autor parece inclinarse hacia una concepción más bien normativa del Derecho. Y ello, porque a la postura que entiende la cuestión de hecho como una subsunción lógica del hecho supuesto bajo el supuesto de hecho de una norma, responde que solo se trata de una subsunción lógica en una pequeña parte; y que "en amplia medida se trata del enjuiciamiento según máximas de experiencia, de la interpretación de actuaciones y declaraciones humanas, de la coordinación tipológica o de una valoración en el marco de una pauta que necesita ser concretizada".

8 Gianformaggio (1973) pp. 186 y ss. También Cfr. Atienza (1993) p. 99, y por supuesto, la obra Perelman, Chaim y Olbrechts-TyTeCa (1994).

${ }^{9}$ Morello (2005) pp. 1 y ss.
} 
como una cuestión de hecho, no había sido revisada por la Corte Suprema mediante el recurso de casación.

\section{B. LA RELACIÓN DE CAUSALIDAD COMO CUESTIÓN DE HECHO}

En general, la división entre las "cuestiones de hecho" y las "cuestiones de derecho" se encuentra referida en la legislación chilena cuando la misma estipula los requisitos de validez que deben cumplir la sentencias (art. 170 CPC.). Pero la misma, aparte de mencionar la distinción, no nos brinda ninguna ayuda a efectos de definir y delimitar cuándo una relación debe ser considerada una cuestión de hecho, y cuándo una cuestión de derecho.

En lo que dice específicamente relación con el tema de la causalidad (causalidad fáctica/causalidad jurídica), y a pesar de que parte de la doctrina había empezado a aceptar la división -otorgándole a la causalidad un componente de derecho- ${ }^{10}$, la jurisprudencia seguía aferrada a la teoría de la contitio sine qua non ${ }^{11}$ al resolver problemas causales. Ello, como se comprenderá, presupone un concepto fáctico de causalidad (causalidad naturalística o mecánica), lo que consecuentemente llevaba a negar la posibilidad de revisar la relación en casación. En términos de la más alta magistratura (fallo de 4 de enero de 1996), "determinar la relación de causalidad es una cuestión de hecho que los jueces del fondo establecen privativamente y que escapa a la potestad del tribunal de casación en el fondo, por cuanto el recurso de casación, por su propia naturaleza, no tiene otra finalidad que la de examinar errores de derecho contenidos en la sentencia sobre la base de los hechos establecidos y considerados en el ámbito exclusivo de sus atribuciones." (Lo subrayado es nuestro) $)^{12}$.

Como se habrá notado, la Corte Suprema mantenía -al menos hasta la aparición del fallo que comentamos- un concepto global de causalidad (suma de lo fáctico y lo jurídico), lo que sumado a la circunstancia de ser considerada en su totalidad una cuestión de hecho (en nuestra opinión perfectamente pudo haber ocurrido lo contrario), llevaba a considerar que la relación no era susceptible de ser revisada, pues en los hechos el tribunal del fondo se reputa soberano.

\section{LA DECISIÓN}

Llegados a este punto, corresponde ahora hacernos cargo de la decisión "sin precedentes” contenida en el fallo que emitió la Corte Suprema el 26 de enero de $2004^{13}$,y que sin duda significa un quiebre con la doctrina mantenida hasta el momento por la más alta corporación de justicia. Esta parte del comentario la dividiremos sustantivamente en dos subapartados que, respectivamente, dicen relación con el cambio de la

\footnotetext{
${ }^{10}$ Entre otros pueden verse, DOMÍngUeZ (2000) pp. 126-127. CORRAL (2003) pp. 191 y ss.

11 Sobre el particular puede verse, BARAONA (2003).

12 Obsérvese que la misma argumentación fue mantenida sistemáticamente entre otras resoluciones en: Corte Suprema (1992) pp. 41 y ss; Corte Suprema (1954) pp. 488 y ss; Corte Suprema (1953) pp. 40 y ss.

13 Corte Suprema (2004) pp. 121 a 136.
} 
línea jurisprudencial que el mismo supone (A); y con las posibles proyecciones que el mismo pueda tener (B).

\section{A. LA RELACiÓN DE CAUSALIDAD COMO CUESTIÓN DE DERECHO}

Efectivamente, el fallo que se analiza viene a variar drásticamente la línea jurisprudencial que unánimemente había mantenido la Corte con anterioridad y que, como se describió más arriba, entendía que la causalidad era una cuestión de hecho no apta para ser revisada en casación. En efecto, ahora la Corte entiende que la relación de causalidad está compuesta sustancialmente tanto por cuestiones de hecho como por cuestiones de derecho, lo que correlativamente equivale a asumir (al menos sobre las cuestiones de derecho), una concepción normativa de la causalidad ${ }^{14}$.

En efecto, la Corte Suprema casa la sentencia de apelación al entender que el juzgador adquo incurrió en error de derecho en cuanto a la imputación normativa del daño al hecho ilícito (lo que técnicamente se denomina imputación objetiva del resultado), y que en el considerando que más interesa a este apartado dice:

"Sexto: Que, con todo, la causalidad es una cuestión estrictamente de hecho en su primer aspecto -el naturalístico-, esto es, entendido como condición necesaria de responsabilidad; pero la atribución normativa del daño al hecho ilícito (daño directo) encierra elementos y aspectos de derecho y, como tal, es susceptible de ser revisado por la Corte Suprema mediante el presente recurso de casación en el fondo." (Nosotros subrayamos).

La sentencia merece un gran reconocimiento, pues efectivamente acaba con una doctrina que, a pesar de tener larga raigambre, se venía denotando obsoleta a efectos de dar respuesta a las nuevas circunstancias causales que un mundo mucho más tecnificado puede dar origen. Y aun cuando la naturaleza del análisis que realizamos no nos permita entrar más en profundidad en las innumerables e interesantísimas aristas que el tema presenta, se debe tener presente que la utilización de un concepto global de causalidad unido a una teoría eminentemente fáctica como la conditio sine qua non, pueda resolver satisfactoriamente los casos simples (aquellos en los que en el hecho ilícito solo se ve involucrada una conducta), la cuestión se torna mucho más compleja en aquellos otros en los que se ven involucradas las llamadas "conductas omisivas", los supuestos de causalidad concurrente ${ }^{15}$, y todos los que dicen relación con la responsabilidad objetiva donde los problemas de la teoría de la conditio sine qua non son de sobra conocidos (regressus ad infinitum).

El fallo también merece nuestros elogios, porque la Corte no varía su antigua postura sin más, sino que, optando por un diferente enfoque metodológico, fundamenta

\footnotetext{
14 Sobre las teorías empíricas como normativas de la causalidad puede verse en la doctrina nacional, CORRAL (2003) pp.179 y ss.

15 Sobre los distintos problemas causales cfr. INFANTE RUIZ (2002) pp. 13 y ss.
} 
de manera consistente el fondo de su resolución. Y es ello así, pues como puede leerse, la Corte pasa de una concepción global de la causalidad a un enfoque bipartito que concibe a la causalidad como un ente constituido por un aspecto fáctico y por otro jurídico, lo que a su vez supone un enfoque mucho más correcto desde un punto de vista técnico ${ }^{16}$. Concordamos pues con la idea de estudiar la causalidad de forma bipartita. Ello nos permite más fácilmente, aunque sea solo idealmente, visualizar el nexo causal desligado en el tiempo (primero lo fáctico y luego lo jurídico), lo que sin duda posibilita mayor precisión en el análisis.

Una vez separada la cuestión fáctica de la cuestión jurídica (imputación), no habría inconveniente, es más, sería recomendable la utilización de la teoría de la conditio sine qua non en cuanto a lo fáctico, y posteriormente, la utilización de una teoría de raigambre normativa, en cuanto a lo jurídico. La conditio sine qua non funcionaría así perfectamente como filtro negativo, pues, si bien no sirve para escoger entre varias causas concurrentes a cual se le debe imputar el resultado, sí sirve para identificar definitivamente a cuáles no (aquellas que suprimidas mentalmente, no varían en nada el resultado).

Llegados a este punto, solo nos queda entonces dilucidar cuál es la teoría normativa que conviene utilizar a efectos de establecer la causalidad jurídica, o lo que es lo mismo, para realizar la imputación del resultado a la conducta del actor.

\section{B. SOBRE LAS PROYECCIONES DEL FALLO: ¿CAUSALIDAD ADECUADA?}

Que las Cortes chilenas hayan tratado superficialmente el tema de la causalidad, y el hecho de que en la mayoría de los casos adhieran sin más a la teoría de la equivalencia de condiciones ${ }^{17}$ es consecuencia obligada, además del fuerte subjetivismo del sistema chileno de responsabilidad civil ${ }^{18}$, de la tradicional consideración de la relación como una cuestión de hecho. En efecto, siendo congruentes consigo mismas, al reputar la relación de causalidad como una cuestión fáctica, la teoría que debía explicarla, debía ser también una teoría fáctica como la equivalencia de las condiciones. A mayor abundamiento, al autoexcluirse la Corte Suprema de revisar el nexo causal por entenderlo fuera de su ámbito de competencia, lo que derechamente conseguía era negarse la posibilidad de influir, ya sea unificando o fomentando la discusión, en los tribunales inferiores, pues ocultaba la teoría causal a la que adhería.

Ello nos lleva a otra de las proyecciones positivas que auguramos al fallo, y es que posibilitada la revisión en casación de la relación de causalidad (al menos en su aspecto normativo), pesará ahora sobre la Corte suprema la responsabilidad de mostrar la teoría causal a seguir, lo que sin duda abrirá un interesante debate que potenciará el estudio de la relación de causalidad y de otros elementos de la responsabilidad civil que comparten frontera con la misma. Por ello, no podemos finalizar este comentario sin intentar el análisis de la teoría normativa que utilizó la Corte Suprema para atribuir el daño al

\footnotetext{
${ }^{16}$ Cfr. Pantaleón (1990) p. 1563.

17 Sobre este punto y otros problemas causales puede verse, BARAONA (2003) pp. 346 y ss.

18 Domínguez (2000) p. 121.
} 
hecho. En nuestro caso, para atribuir el perjuicio económico que supuso la frustración de la vía ejecutiva que preparaba la sociedad demandante, nada menos que a la conducta negligente del banco que no verificó correctamente el domicilio de su cuentacorrentista.

Primeramente, hay que advertir que la tarea que nos proponemos no resulta nada fácil, ya que además de no explicitar la sentencia la teoría que emplea (causalidad necesaria, causalidad adecuada, imputación objetiva, etc.), la misma utiliza una terminología bastante ambigua. Con todo, y conscientes de lo arriesgado del diagnóstico, pensamos que la Corte utiliza la teoría de la causalidad adecuada, pues cuando afirma en su considerando séptimo,

"que el daño sufrido por la sociedad demandante, en la especie, consiste en la pérdida de las acciones legales y fundamentales para su cobro, siendo la acción criminal el principal medio que poseen los acreedores para obtener el pago de los créditos, lo que, además, es motivo evidente de su amplia aceptación en el mundo comercial y lo distingue de otros instrumentos dentro del sistema económico; todo lo cual hace concluir que tal situación está en estricta y directa relación con la actuación negligente de la entidad financiera demandada" (nosotros subrayamos),

pensamos que lo que está diciendo la Corte Suprema, es que el daño (el menoscabo económico que se produjo a la sociedad por haberse malogrado la acción criminal) se puede imputar a la conducta negligente del banco (no haber comprobado correctamente el domicilio del girador), ya que según el curso habitual de las cosas y la experiencia de la vida ("siendo la acción criminal el principal medio que posen los acreedores para obtener el pago de los créditos...”), esa conducta del banco es capaz de producir el efecto dañoso que se ha realizado ${ }^{19}$.

De ser cierto lo que acabamos de decir, entonces nuevamente el fallo merecería nuestros aplausos, pues se estaría aplicando correctamente la teoría de la causa adecua$\mathrm{da}^{20}$, donde lo realmente importante no es que el banco hubiese podido predecir o prever las consecuencia dañosas, sino, y desde otra perspectiva, que la causa aparezca retrospectivamente como objetivamente apta para provocarlas.

La teoría de la causa adecuada no solo representa un avance desde un punto de vista técnico respecto de la teoría de la equivalencia de las condiciones, sino que también se adapta y logra explicar más fácilmente el nexo causal en un mundo mucho más tecnificado, en el que, además, parece darse un tránsito (en la identificación de la

\footnotetext{
19 En este caso efectivamente la Corte Suprema estaría utilizando un criterio normativo, relacionado con este punto, Nino (1991) p. 205, se remite a HART y HONORÉ, R. A. de la siguiente manera:

"Ellos (HART y HONORÉ) comienzan por decir que lo que es tomado como normal no solo depende del curso de la naturaleza, sino también de la ocasión, de los hábitos, de las costumbres y las convenciones humanas. Esto es así, argumentan, porque los hombres han descubierto que la naturaleza puede causarnos daño no solo si interferimos con ella, sino también en otras situaciones, si no intervenimos; debido a eso hemos desarrollado técnicas, procedimientos y rutinas de comportamiento para prevenir tales daños. Cuando las condiciones normales desarrolladas por los seres humanos son establecidas, una desviación de las mismas se ve como algo excepcional, y puede considerarse la causa del daño. Tal desviación de las normas creadas por los seres humanos frecuentemente es una omisión, esto es, una abstención de actuar del modo esperado o requerido por la norma”.
} 
conducta jurídicamente relevante) desde la teoría de la acción humana hacia posturas funcionalistas como la de la "defraudación de las expectativas de confianza"21. Ciertamente, y como al respecto de esta teoría anota LE TORNEAU, "el carácter totalmente artificial y abstracto del examen retroactivo debería servir para no admitir esta teoría si no es con prudencia y circunspección" 22 .

Por nuestra parte, solo nos queda ahora esperar que el alto tribunal retome el tema causal y nos muestre con claridad cuáles son los criterios causales a los que adhiere.

Fecha de recepción: 27 de octubre 2005

Fecha de aceptación: 26 de enero 2006

\section{BIBLIOGRAFÍA CITADA}

AlesSANDRi Rodríguez, Arturo (1943): De la responsabilidad extracontractual en el derecho civil chileno (Santiago, Imprenta Universitaria).

ARAYA JASMA, Fernando (2003): La relación de causalidad en la responsabilidad civil (Santiago, Ed. LexisNexis).

AtienZA, Manuel (1993): Las razones del Derecho. Teorías de la argumentación jurídica (Madrid, Ed. Centro de Estudios Constitucionales).

BARAONA, Jorge (2003): "La causa del daño en la jurisprudencia reciente", Revista Chilena de Derecho, vol. 30, no 2: pp. 345 a 379.

CORRAL TALCIANI, Hernán (2004): "La relación de causalidad en el sistema de torts del Common Law", AA.VV., Nuevas tendencias del Derecho (Santiago, Ed. LexisNexis).

CORRAL TALCIANI, Hernán (2003) "Lecciones de responsabilidad civil extracontractual, (Santiago, Editorial Jurídica de Chile).

De Cuevillas Matozzi, Ignacio (2000): La relación de causalidad en la órbita del derecho de daños (Valencia, Ed. Tirant lo Blanch)

Domínguez ÁGuila, Ramón (2000): "Aspectos de la relación de causalidad en la responsabilidad civil con especial referencia al derecho chileno", Roma e America Diritto Comune, 10/2000, Mucchi Editore: pp. 115-127.

GERI, Vinicio (1967): Responsabilità Civile per dan a cose ed animali (Milano, Ed. Giuffré)

Gianformaggio, Leticia (1973): Gli argomenti di Perelman: dalla neutralità dello scienziato all'imparzialita del giudice (Milano, Ed. Comunità).

Grossi, Paolo (2003): Mitología jurídica de la modernidad (trad. de Manuel MARTíneZ, Madrid, Ed. Trotta).

20 Téngase presente que la teoría de la causa adecuada es la teoría causal que goza de mayor aceptación el en derecho comparado, y que incluso en Argentina ha logrado consagración legislativa

21 Sobre el tema puede verse entre otros, JaKobs (1996); HruschKa (2004); Luhmann (1997); Del mismo autor (1996).

22 Le Torneau (2004) p. 83. 
HRUSCHKA, Joachim (2004): Reglas de comportamiento y reglas de imputación, Seminario internacional de Derecho penal, organizado por la Carrera de Abogacía de la Universidad Blas Pascal - Cátedra de Derecho Procesal Penal. Córdoba - Argentina, 10 de marzo de 2004.

INFANTE RUIZ, Francisco José (2002): La responsabilidad por daños: nexos de causalidad y causas hipotéticas (Valencia, Ed. Tirant lo Blanch).

JAKOBS, Gunter (1996): Sociedad norma y persona en una teoría funcional del derecho penal (trad. Cáncio Melia y Feijóo Sánchez, Madrid).

LARENZ, Karl (2001): Metodología de la ciencia del Derecho (trad. de RodRíGUEZ MOLINERO, Barcelona, Ed. Ariel).

Le Torneau, Philippe (2004): La responsabilidad civil (trad. de Javier TAmayo JaraMILlO, Ed. Legis).

Luhmann, Niklas (1996): Confianza (México, Ed. Anthropos).

LuHMANN, Niklas (1997): Sociedad y sistema: la ambición de la teoría (trad. de Santiago LÓPEZ PeTIT y Dorothee SCHMiTZ, Barcelona, Ed. Paidós).

Morello, Augusto (2005): "El mito de las cuestiones de hecho y de derecho en la casación”, La Ley, No 188.

NinO, Carlos Santiago (1991): The ethics of human rights (Oxford).

PANTAlé́n PRIETO, Fernando (1990): "Causalidad e imputación objetiva: criterios de imputación objetiva", Centenario del código civil, Asociación de Profesores de Derecho Civil, t. II (Madrid, Centro de Estudios Ramón Arces).

Perelman, Chaim y Olbrechts-Tyteca, L. (1994): Tratado de la argumentación. La nueva retórica (trad. de Julia SEVIlla MuÑoz, Madrid, Ed. Gredos).

\section{NORMAS CITADAS}

Código Civil, artículos 2314, 2316 y 2318. Diario Oficial, 1854.

Ley No 18.290, de Tránsito. Diario oficial, 7 febrero 1984.

Ley No 18.575, de Bases Generales de la Administración del Estado, Diario Oficial, 5 diciembre 1986.

Ley No 19.300 , de Bases Generales del Medio Ambiente, Diario Oficial, 9 marzo 1994.

\section{JURISPRUDENCIA CITADA}

Corte Suprema (1953): sentencia 14 de abril de 1953, Revista de Derecho y Jurisprudencia, t. 50 , secc. $4^{\mathrm{a}}$, pp. 40 y ss.

Corte Suprema (1954): sentencia 16 de octubre de 1954, Revista de Derecho y Jurisprudencia, t. LI, secc. $1^{\text {a }}$, p. 488.

Corte Suprema (1992): sentencia 7 de mayo de 1992, Revista de Derecho y Jurisprudencia, t. 89 , secc. $1^{\text {a }}$, pp. 41 y ss.

Corte Suprema (1996): sentencia 4 de enero de 1996.

Corte Suprema (2004): sentencia 26 de enero de 2004, Gaceta Jurídica, no 283, enero, 2004, pp. 121 a 136. 